\title{
Archival Context, Digital Content, and the Ethics of Digital Archival Representation
}

\author{
Jane Zhang \\ School of Library and Information Science, Catholic University of America, \\ Washington DC 20064, <zhangj@cua.edu>
}

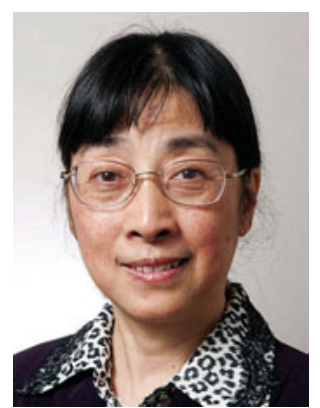

Jane Zhang is an assistant professor in the School of Library and Information Science, Catholic University of America, Washington D.C. She holds a PhD from Simmons College, Boston, and a joint Master of Archival Studies and Library and Information Studies from University of British Columbia, Canada. Her teaching and research areas include records and recordkeeping, archival theory and practice, electronic records, and digital archives. She worked at Harvard University Archives and University of Calgary Archives before joining the faculty at Catholic University.

Zhang, Jane. Archival Context, Digital Content, and the Ethics of Digital Archival Representation. Knowledge Organization. 39(5), 332-339. 26 references.

ABSTRACT: The findings of a recent study on digital archival representation raise some ethical concerns about how digital archival materials are organized, described, and made available for use on the Web. Archivists have a fundamental obligation to preserve and protect the authenticity and integrity of records in their holdings and, at the same time, have the responsibility to promote the use of records as a fundamental purpose of the keeping of archives (SAA 2005 Code of Ethics for Archivists V \& VI). Is it an ethical practice that digital content in digital archives is deeply embedded in its contextual structure and generally underrepresented in digital archival systems? Similarly, is it ethical for archivists to detach digital items from their archival context in order to make them more "digital friendly" and more accessible to meet needs of some users? Do archivists have an obligation to bring the two representation systems together so that the context and content of digital archives can be better represented and archival materials "can be located and used by anyone, for any purpose, while still remaining authentic evidence of the work and life of the creator"? (Millar 2010, 157) This paper discusses the findings of the study and their ethical implications relating to digital archival description and representation.

Received 16 July 2012; Accepted 16 July 2012

\subsection{Codes of ethics for archivists and archival arrangement and description}

Archivists are often called upon to make difficult ethical decisions about their professional practices. This explains why discussions on ethical issues are broad and diverse in archival literature. Surprisingly, this has not been the case for the area of archival information organization. Of the several versions of professional ethical codes for archivists drafted in this country, most of them do not contain explicit provisions on archival arrangement and description. Discussions exclusively on ethical issues concerning archival arrangement and description are rarely seen in the archival literature, historically and presently.
The earliest professional code for archivists was written in 1955 by Wayne C. Grover, then the Archivist of the United States, initially for internal use of the National Archives and later published for dissemination to the archival profession. The 1955 code was "organized around seven points reflecting archival functions such as appraisal, security, reference, and access" (Benefit 1988, 177). However, there was an obvious omission of the core archival function of arrangement and description, except for a brief mentioning of obligation to make archival holdings known to users "through published finding aids" in the provision for access (Danielson 2010, 31). It was not until 1980 that the first Code of Ethics for Archivists was approved by the Society of American Archivists (SAA). The 1980 Code introduces new pro- 
visions and emphasizes basic archival functionsincluding arrangement of archival materials to be processed "in conformity with sound archival principles and [proceeding] as rapidly as ... resources permit" (Benedict 1988, 181).

The 1980 Code was revised and expanded into the 1992 Code, which contained twelve provisions. The updated code emphasizes the ethical role of archivists to "maintain and protect the arrangement of documents and information transferred to their custody to protect its authenticity," and "establish intellectual control over their holdings by describing them in finding aids and guides to facilitate internal control and access by users of the archives" (SAA 1992, 1314). Although the function of arrangement is part of Section VI (Appraisal, Protection and Arrangement), Section V of the Code is exclusively entitled "Description"- a completely new section added to the 1992 Code that addresses the function directly for the first time (Cain 1993, 48). Included in the commentary that accompanies the provision text is also the notion of the obligation of archivists to "facilitate the use of their collections and make them known"- "it is not sufficient for archivists to hold and preserve materials" and "excessive delay in processing materials and making them available for use would cast doubt on the wisdom of the decision" if institutions acquire materials but "do not have the resources to process those materials or store them properly" (SAA 1992, 13-14).

The 1992 Code was "drastically reduced" into the 2005 Code to reflect the profession's changing policy of "providing an aspirational code rather than enforcing ethics with penalties" (Danielson 2010, 40). As a result, specific provisions on archival arrangement and description were replaced by a few general statements. Ethical archivists "should exercise professional judgment in acquiring, appraising, and processing historical materials." They have "a fundamental obligation to preserve and protect the authenticity and integrity" of records in their holdings, and at the same time "recognize their responsibility to promote the use of records as a fundamental purpose of the keeping of archives" (SAA 2005, V \& VI). In spite of the inclusion of the Core Values of Archivists to be used together with the most recent revision of Code of Ethics for Archivists (SAA 2012), little has been added in the 2012 Code in regard to the ethical role archivists should play in the organization and representation of archival materials.

Consistant with the general and vague nature of ethical dimensions for archival arrangement and description in the development of ethical codes for archivists, very few authors in archival literature address ethical concerns directly relating to archival information organization, especially its description system. When they occasionally discuss these issues, most tend to question soundness of programs and correctness of individual applications such as impartial/unbiased processing, restriction implementation, accurate and authentic information, and adherence to standards (Benedict 2003; Cain 1993; Danielson 1997, 2010) rather than responsiveness of descriptive systems. Archivists generally consider it ethical to organize and describe archival materials collectively based on the established archival principles and use other tools, such as selective name and content indexing to supplement and assist content access (Cain 1993, 45).

\subsection{Archival description: context and content represented in one structure}

The structure of archival description has not been seriously challenged ethically in its development over the century. Archivists in the last quarter of the nineteenth century in Europe and archivists at the beginning of the twenty-first century in North America saw eye to eye with each other when they found "a living organism" in each archival fonds organized by the newly issued principle of provenance in 1881 (Posner 2006a, 41) and "a data structure standard to accommodate hierarchies of archival descriptions" in the Encoded Archival Description (EAD) first released in 1996 (Haworth 2001, 7). For over a century, archivists in Europe and North America have been guided by a series of archival principles and rules that help them to develop archival description as a common structure for representing both context and content of archival records so that the essential qualities of archival records can be "preserve [d], perpetuate[d], and authenticate[d]" over time and the meaning in them can be made "available and comprehensible to all userspresent and potential" (MacNeil 1995, 30).

The principle of provenance mandates that records of the same origin should be processed as one record group and not be intermingled with records of other origins when accessioned, organized, and described into archival collections. The principle (along with the principle of original order) was developed in Europe during the second half of the nineteenth century and formulated in the archival manual published by three Dutch archivists in 1898 (Muller et al. 2003). By following the principle, archivists are able to provide the most comprehensive representation of archival records of an originating body and address the questions of 
who, where, when, how, why, and what- that relate to those records. It helps to place the record in a context so that its content becomes comprehensible, its interpretation accurate, and its relationship meaningful.

Not only should records of the same origin be grouped together, they should also be kept in the way they are organized for their creation purposes. This has been made explicit in the principle of original order, which ensures that any meaningful organizational structures imposed by records creators should not be disturbed after records are transferred to archives. Maintaining records in original order serves two purposes, as Richard Pearce-Moses (2005, 280-281) explains in his Glossary of Archival and Records Terminology: "First, it preserves existing relationships and evidential significance that can be inferred from the context of the records. Second, it exploits the record creator's mechanisms to access the records, saving the archives the work of creating new access tools." By providing evidence and facilitating access, original order combines context and content in one representation structure and serves the dual role of archivists "as responsive to the needs of the creator of the record as to later users" (Pugh 1982, 34).

An important notion derived from the implementation of the principles of provenance and original order in the twentieth century is the development of the concept of levels of control (Miller 1990). Archival arrangement guided by multi-level control breaks down archival holdings into five hierarchical levels of depository, record group, series, filing unit, and document so that each document has its natural place and its association and relation with other documents remain clear (Holmes 1964). The practice highlights the interrelations of all levels of control and emphasizes the role of aggregate levels in making sense of archival records because "individual file units cannot be fully understood without an understanding of the larger aggregates" (Miller 1990, 28). Closely associated with the concept of levels of control are multilevel description rules specified in $\operatorname{ISAD}(G)$ : General International Standard Archival Description (ICA 2000). Accordingly, archival collections must be described from the highest (general) to the successively lower (specific), each lower level of description, if provided, must be identified and linked to its immediate higher level, and, to avoid redundancy, information given at a higher level should not be repeated at lower levels (ICA 2000, 12).

Archival multilevel description provides archivists with a technical solution for seamlessly holding the whole and its successive parts of archival collections in their holdings in one master representation system.
The context-based hierarchical representation accommodates content access by "producing leads to files which are searched by using their internal structures" (Lytle 1980, 64). Additional content access points such as names, places, subjects, forms, geographic locations, and time periods, if created, can be used as supplementary tools (SAA 2004, xix; Roe 2005, 80). In this system of hierarchy, context and content are represented as a coherent whole. Everything else (i.e., additional access tools) will lead users to the whole, and the whole then guides users to its parts. And most important of all, as a context-based access system, the whole has the capacity to hold all its parts accountable, traceable, and findable. This eventually helps archivists to fulfill their dual obligations to "preserve the intellectual and physical integrity" of records in their holdings and at the same time "promote the use of records as a fundamental purpose of the keeping of archives" (SAA 2005).

\subsection{Digital archival representation: a typological study}

Traditional archival description embodies a representation system in which context and content of archival records are organized as an organic whole and represented in a coherent structure. However, a discrepancy has been observed in a recent study completed by the author that raises some ethical concerns relating to digital archival representation. The study was designed to investigate how archivists organize and present archival collections that are digitized partially or entirely and the major approaches adopted by them to incorporate digital object metadata into digital archival description. Funded by an internal grant, the researcher systematically searched and collected 276 digital collection sites posted online by university special collections and archives (70 percent); public libraries (25 percent); state and municipal archives (8 percent); and historical societies, museums, and private archives ( 13 percent). Of the 276 digital collections selected in this study, 209 (73 percent) have identifiable content management systems. Among them, the majority of the sites use CONTENTdm and consequently Dublin Core to organize and represent digital collections. This indicates that the general trend in the movement of digitization is to organize and describe primary resources individually using item-level metadata.

How would archivists handle archival context in this metadata-centric digital collection description environment? To what degree is description/metadata of 
digital items integrated into archival description system? From the 276 digital collection sites, 27 examples of digital archival collections were selectedcollections consisting of provenance-based institutional records or personal papers and showing efforts to present both archival context and digital item content. Of the 27 digital archival collections, nine collections adopt an embedded model to represent digital content in archival context; that is, archival finding aid serves as the main access interface while digital objects are linked to the hierarchical structure at various levels. Fifteen collections adopt a segregate model to facilitate more direct access to digital content, that is, multifaceted metadata serves as the main access point for users to search or browse the content of digital collections, and archival finding aids mostly exist as an external link to provide additional historical and documentary background to digital materials. Three collections adopt a parallel model to represent digital content in two separate interfaces; that is, digitized items are directly linked to online finding aids and, at the same time, made searchable or browsable by various metadata specific fields to serves different user communities.

\subsection{Digital archival representation: ethical concerns}

The findings of the study as shown in the three representation models (embedded, segregate, and parallel) reveal a growing conflict of archival context and digital content in digital archival representation, and put into question the balance of context and content maintained in traditional archival description that archivists rely on to perform their dual obligations of preserving and protecting the authenticity and integrity of their holdings and promoting the use of records as a fundamental purpose of the keeping of archives. Each of the three models has achieved a certain level of integration of context and content. However, the representation decisions made are far from ideal and some ethical concerns can be raised for each model as discussed in this section.

\subsection{Is it an ethical practice that digital content in digital archives is deeply embedded in its contextual structure and generally underrepresented in digital archival systems?}

The common characteristic of the embedded representation model is that archival description serves as the main access interface while digital objects are linked to and embedded in the hierarchical structure at various levels as appropriate. The design of this model inherits the traditional archival principle of describing archival materials from the general to the specific. The representation system is contextual, hierarchical, and mostly linear (non-faceted). The system guides users from archival context to digital content and helps them to achieve a fuller understanding of meaning of archival records in the context of their creation. Digital objects, when embedded at their appropriate aggregate levels in archival finding aids, can be retrieved and interpreted contextually so that loss of archival meaning can be minimized.

However, due to the nature of traditional archival description, digital content representation in this model is minimal and hidden at the bottom of the hierarchy rather than made obvious at the front. By embedding digital objects in traditional archival hierarchy with minimal discovery metadata, this model offers limited accessibility to its digital content. Users need to follow the hierarchy to browse the multi-level description before they gain access to digital content. Search capacity for digital content is limited due to the fact that the model is not built with searchable metadata to enable specific field search.

In the pre-digital age, physical records are filed as functional groups with limited description to meet business and personal recordkeeping needs. Archival description systems developed as such prove to be sufficient in accommodating both context representation and content description of those records. However, what used to be justified ethically in what archivists do may not be the case anymore, especially when archival collections comprised of digital objects have more granular metadata than the current system is able to represent. When paper records are turned into digital to increase accessibility, it is often the case that they are supplied with additional descriptive metadata. It is even more often the case that born-digital materials are created with metadata very much different from that of their paper counterparts. If the same representation system continues to be used without adjustment as shown in the embedded model, digital objects can be easily underrepresented. In other words, existing discovery metadata have to be made hidden in the digital representation system built on the traditional model. This may not be a right thing for archivists to do because the practice serves neither the original purpose of records creators nor the information search needs of current or future users. Archivists may feel obliged at some point, consciously or subconsciously, to question the inclusiveness of the system and address this representation issue ethically. 


\subsection{Is it ethical for archivists to detach digital items from their archival context in order to make them more "digital friendly" and more accessible to meet changing use expectations?}

Most of digital archival collections identified in this study do not rely on the hierarchical structure of archival description to represent and display digital content of archival materials. Instead, a different representation system has been constructed to facilitate more direct access to digitalized archival items. In this model, description of digital objects, in the form of multi-faceted metadata, serves as the main access point for users to search or browse the content of digital collections. Archival context, in the form of online archival finding aids, mostly exists as an external link to provide additional historical and documentary background to digital materials. In an effort to promote its accessibility, digital content has been segregated from its original context and the latter has been de-emphasized into a secondary position for users to refer to if they need more information.

The segregate model of digital archival representation provides more flexibility to the representation and access of digital content. The model allows for more specific descriptive information about digital items, such as title, subject, description, author, creator, recipient, contributor, date, place, and material type. Moreover, the practice helps to bring standardization to the description of digital items. The standard practice increases accessibility of digital content in a digital collection and, more importantly, enables interoperability across collections in the digital archival and library community and beyond.

An obvious disadvantage of the segregate model is that archival description loses its position as a primary gateway for access to digital items. The model increases the accessibility of digital content, but decreases the centrality of archival context in digital archival representation. Having lost its central role in archival information retrieval, an archival finding aid only exists as an external link to provide users with additional background information if needed, which could easily be bypassed, ignored, or simply unnoticed-something most archivists would consider unethical because it would turn their collections less or no longer archival. Elena Danielson, author of a recent SAA publication The Ethical Archivist (2010) and an archivist who has spent her life-long career exploring archival ethics, thus warned us many years ago in her paper "Ethics and Reference Services" when she commented on the new challenges faced by reference archivists in "scanning photographs and documents onto compact disks and into Web sites" (1997, 116-117):

A verbatim document facsimile has all the appearance of truth, but without a context, even an authentic document or photograph can be very misleading.... One of the sacred principles of archives has been to preserve the position of a document within a hierarchy, often dictated by the organizational structures that created the papers originally. Internet facsimiles lose this context. The browser is forced to assume that a document is both representative and not manipulated. As a result, disjointed snippets of information are often misleading.... In their eagerness to participate in the Internet revolution, and to make their collection accessible, reference archivists must guard against inadvertently contributing to a distorted history.

\subsection{Is it ethical to distinguish between context-based scholarly use and content-based public use of digital archival materials and produce parallel representation systems to meet different use needs?}

A small number of digital archival collections identified in this study manage to use both online finding aids and searchable item-level metadata to represent and display digital objects. A typical example is Online Archive of California (OAC) (http://www. oac.cdlib.org/) and its companion web site, Calisphere (http://www.calisphere.universityofcalifornia. $\mathrm{edu} /$ ). OAC is a repository of online archival finding aids with embedded digital objects. Calisphere is a website that offers educators, students, and the public access to digital primary sources. The content in Calisphere is drawn from the digital content in the Online Archive of California. However, rather than keeping them buried in archival finding aids, Calisphere repurposes digital materials by reorganizing them in a way that "best serves general users and $\mathrm{K}-12$ audiences." The redesign "frees the OAC to focus on being purely a site for researchers." The idea of two sites that serves two user communities is clearly articulated on the project website (CDL n.d., para. 7):

These two websites exist because they serve two very different user needs. For research-oriented users who want to go beyond what is available online and locate the actual, physical item, the $\mathrm{OAC}$ is the best starting point. For users whose 
primary interest is to view digitized images and documents, Calisphere is a place to explore online content. In addition, Calisphere provides K-12 educators with a subset of content organized and aligned with California Content Standards.

The two digital collection sites represent a parallel representation model that aims to make digital content searchable as individual items as well as contextualized in archival descriptive framework. However, evidence shows that they may have to stay apart as separate interfaces, and, arguably, serve different use purposes. Traditional archival processing considers it an ethical practice to stick to archival principles while using alternative representation tools to meet specific use needs. As explained by Virginia Cain (1993, 45), archival processing work should always begin with consideration of the principles of provenance and original order and should always be done with impartiality:

Arrangement and description should not be tailored to the wishes of a single researcher, who might wish to find all correspondence of a single individual or all speeches on a particular topic located together. If a collection contains a large run of chronologically arranged correspondence on a wide variety of topics, the archivist will not rearrange the papers to suit a researcher who may wish to read only letters on certain topics or exchanged with certain individuals. Instead, the archivist seeks other tools, such as selective name and content indexing, to provide intellectual access and linkages in a way that the physical arrangement of the papers cannot.

If archivists accept the practice of using selective name and content indexing to provide intellectual access to archival materials, will they agree that digital archives can be organized by different principles to meet needs of different user groups? The parallel representation model distinguishes between contextbased scholarly use and content-based public use of archival materials. The assumption is that nonscholarly users may not need archival context when they use digital objects, therefore, digital content can be repurposed, that is, reorganized without consideration of its originating context. Would this be accepted as an ethical professional practice? Do we have a better way of doing our work?

\subsection{Do archivists have obligations to bring the two representation systems together so that the context and content of digital archives can be better represented and archival materials "can be located and used by anyone, for any purpose, while still remaining authentic evidence of the work and life of the creator"? (Millar 2010, 157)}

Implied in the three representation models (embedded, segregate, and parallel) is a challenging situation that archival hierarchical structure and digital descriptive metadata are representation systems of a different nature that may be difficult to accommodate each other. This is hardly something new. The debate about the conflict of provenance-based and subject-based information organization principles and practices has spread for more than a century in modern archival history. It can be traced back to the early nineteenth century in the newly established national archives of France when "the archivists devoted most of their time and work, their efforts and interests to arranging and cataloging medieval documents" at the expense of dissolving the fonds of the old regime in order to make the archives accessible to the public (Posner 2006b, 30-31). The same trend can be observed in the development of manuscript repositories and public archives in the U.S where "variations on the chronologicaltopical/geographical classification system prevailed without serious challenge until the first decade of the twentieth century" before "the European practice of classifying records by the source of their creation" was introduced and accepted in the first half of the twentieth century (Berner 1983, 13).

The debate continues even after the provenancebased system has been well established as the principal means of accessing archival information. Archivists question whether the dominant use of provenance "reflects desirability or merely archivists' failure to design alternative subject retrieval systems" (Ruth 1988, 273). They understand the power of provenance as "an inferential system of information" and the same time recognizes that "there is a higher probability that information being sought" exists "at each successive level of control” (Berner 1983, 116). While the content of public records can sometimes be inferred from the contextual description of functional and organizational responsibilities, non-provenance access points such as subject/topic, occupation/function, and type of material are very powerful access points to the hidden content of private records (Beattie 1997, 88-92). Concerns have also been raised over the lacking of the system to "bring together the 
access points" in "information/records management and archival management" systems (Berner 1986, 5).

When digital reality turns archival materials into digital objects, their creation, use, management, preservation, and reuse in the current practice are increasingly metadata-dependent, and very often at the individual item level. It may be an appropriate time now for archivists to make a professional call to incorporate item-level metadata into descriptive standards because, not only they are integral components of records when they are initially created and used, they are also what future users depend on to locate information that is contained in them. In exploring a code of ethics for cataloging, Sheila Bair (2005) considers it an ethical dimension for catalogers to "actively participate in the development, reform, and fair application of cataloging rules, standards, and classification, as well information-storage and retrieval systems" (16). When archives have records that are associated or supplied with more descriptive metadata than traditional archival description required, it is the archivists' professional obligations to look into possibilities to make their descriptive systems more inclusive. An ethical system of digital archival representation should be the one that accommodates both archival context and digital content and capable of facilitating quick and easy location of information that is accurate and authentic to serve multiple types of users for multiple purposes as indicated by Laura Millar in her recent SAA awarded book Archives: Principles and Practices $(2010,157)$.

\subsection{Conclusion}

The balance of context and content in archival description, though not new, has been highlighted in digital archival representation as descriptive metadata become important components of records in digital environments. To obtain the status of relevancy in the digital world, archivists cannot afford "all context and no content" or "more context and less content" approach. The issue may become so crucial with an ethical dimension that requires careful deliberation to maintain the balance-going to the extreme of either direction would be doing harm to the profession. There would be no archival profession without an appropriate control of archival context, and there would be no future of archival profession if no effective effort could be made to optimize access to digital content in digital archival collections. It is the ethical responsibilities of archivists to provide users with easy access to information from their holdings and at the same time maintain the public trust for the authenticity of information they provide for users. This speaks for the value of the work they do as professional archivists and their contributions to the good and justice of the society.

\section{References}

Bair, Sheila. 2005. Toward a code of ethics for cataloging. Technical services quarterly 23: 13-26.

Beattie, Diane. 1997. Retrieving the irretrievable: providing access to "hidden groups" in archives. In Cohen, Laura B. ed., Reference services for archives and manuscripts. New York: Haworth Press, pp. 8394.

Benefit, Karen. Archival ethics. 1988. In Bradsher, James Gregory ed., Managing archives and archival institutions. London: Mansell Publishing, pp. 17484.

Berner, Richard C. 1983. Archival theory and practice in the United States: a historical analysis. Seattle: University of Washington Press.

Cain, Virginia J.H. 1993. The ethics of processing. Provenance XI: 39-55.

California Digital Library (CDL). Calispher. http:// www.cdlib.org/services/dsc/calisphere/.

Danielson, Elena S. 1997. Ethics and reference services. In Cohen, Laura B. ed., Reference services for archives and manuscripts. New York: Haworth Press, pp. 107-124.

Danielson, Elena S. 2010. The ethical archivist. Chicago: Society of American Archivists.

Haworth, Kent M. 2001. Archival description: content and context in search of structure. Journal of Internet cataloging 4n3/4: 7-26.

Holmes, Oliver W. 1964. Archival arrangement - five different operations at five different levels. American archivist 27: 21-42.

International Council on Archives (ICA). 2000. $\operatorname{ISAD}(G)$ : general international standard archival description, $2^{\text {nd }}$ ed. Available http://www.icacds.org. uk/eng/ISAD $(\mathrm{G})$.pdf.

Lytle, Richard H. 1980. Intellectual access to archives: I. provenance and content indexing methods of subject retrieval. American archivist 43: 64-75.

MacNeil, Heather. 1995. Metadata strategies and archival description: comparing apples to oranges. Archivaria 39: 22-32.

Miller, Fredric M. 1990. Arranging and describing archives and manuscripts. Chicago: Society of American Archivists. 
Millar, Laura. 2010. Archives principles and practices. New York: Neal-Schuman Publishers.

Muller, Samuel, Feith, Johan A., and Fruin, Robert. 2003. Manual for the arrangement and description of archives. Chicago: Society of American Archivists.

Pearce-Moses, Richard. 2005. A glossary of archival and records terminology. Chicago: Society of American Archivists.

Posner, Ernst. 2006a. Max Lehmann and the genesis of the principle of provenance. In Munden, Ken ed., Archives and the public interest: selected essays. Chicago: Society of American Archivists, pp. 36-44.

Posner, Ernst. 2006b. Some aspects of archival development since the French Revolution. In Munden, Ken ed., Archives and the public interest: selected essays. Chicago: Society of American Archivists, pp. 23-32.

Pugh, Mary Jo. 1982. The illusion of omniscience: subject access and the reference archivist. American archivist 45: 33-44.
Roe, Kathleen D. 2005. Arranging $E$ describing archives $E$ manuscripts. Chicago: Society of American Archivists.

Ruth, Janice E. 1988. Educating the reference archivist. American archivist 51: 266-76.

Society of American Archivists (SAA). 1992. Code of ethics for archivists. In Provenance XI, 1993: 3-20.

Society of American Archivists (SAA). 2005. Code of ethics for archivists. http://web.archive.org/web/ 20110725013613/http://www2.archivists.org/code -of-ethics.

Society of American Archivists (SAA). 2012. SAA core values statement and code of ethics. Available http://www2.archivists.org/statements/saa-corevalues-statement-and-code-of-ethics.

Society of American Archivists (SAA). 2004. Describing archives: a content standard. Chicago: The Society of American Archivists. 